\title{
钯/手性降冰片烯协同催化高效构建轴手性化合物
}

\author{
张子玉 王晓晨* \\ (南开大学化学学院 天津 300071)
}

\section{Construction of Axial Chirality via Palladium/Chiral Norbornene Cooperative Catalysis}

\author{
Zhang, Ziyu Wang, Xiaochen* \\ (College of Chemistry, Nankai University, Tianjin 300071)
}

轴手性联芳基结构 ${ }^{[1]}$ 常见于各类功能材料、天然产 物、药物分子和手性配体/催化剂. 因此, 联芳基化合物 的对映选择性合成一直备受关注, 相关研究已取得较大 进展, 然而, 已知方法均采用官能团化的特定底物或复 杂结构的催化剂, 所以应用范围受限. Itami ${ }^{[2]}$ 、Wald$\operatorname{mann}^{[3]}$ 和 Cramer ${ }^{[4]}$ 等课题组的开创性工作表明, 不对称 $\mathrm{C}\left(\mathrm{sp}^{2}\right)$ - $\mathrm{H}$ 芳基化反应是直接合成轴手性联芳基化合物 的一种高效而简便的方法, 然而, 由于原料的空间位阻 较大, 反应很难兼顾活性和立体选择性.

Catellani 反应是金属-有机小分子协同催化的典型 代表, 可通过 $\mathrm{C}\left(\mathrm{sp}^{2}\right)-\mathrm{H}$ 芳基化构筑联芳基结构 ${ }^{[5]}$. 然 而, 催化不对称 Catellani 反应是一个极具挑战性的全新 研究领域, 目前仅有少数的研究报道. 近日, 武汉大学 化学与分子科学学院周强辉课题组 ${ }^{[6]}$ 利用钯和手性降冰
片烯 $\left(\mathrm{Pd} / \mathrm{NBE}^{*}\right)$ 协同催化成功构建轴手性联芳基化合物 (Scheme 1). 反应经历如下几步: 芳基碘化物与钯催化 剂和 $\mathrm{NBE}^{*}$ 反应形成手性 ANP 中间体 I; I 与 2,6-二取代 芳基溴化物发生氧化加成生成中间体 II; II 发生还原消 除和 $\beta$-C 消除生成关键的轴手性钯中间体 III 并释放 $\mathrm{NBE}^{*} ;$ III 可以与外加终止试剂反应生成轴手性联芳基 化合物 4, 也可以发生分子内终止反应生成手性荡醇化 合物 5.

该方法具有广泛的底物兼容性. 首先, 作者对终止 试剂的适用性进行了考察, 带有拉电子基团和给电子基 团的烯烃都可以得到目标产物，且反应兼容酯基、醛基、 酰胺基、苯磺酰基、醇、硝基、杂芳基等官能团，对映 选择性都非常优异( $96 \%$ \% $99 \%$ ee). 反应也可以兼容一 些药物分子衍生的苯乙烯, 得到复杂结构的轴手性联芳

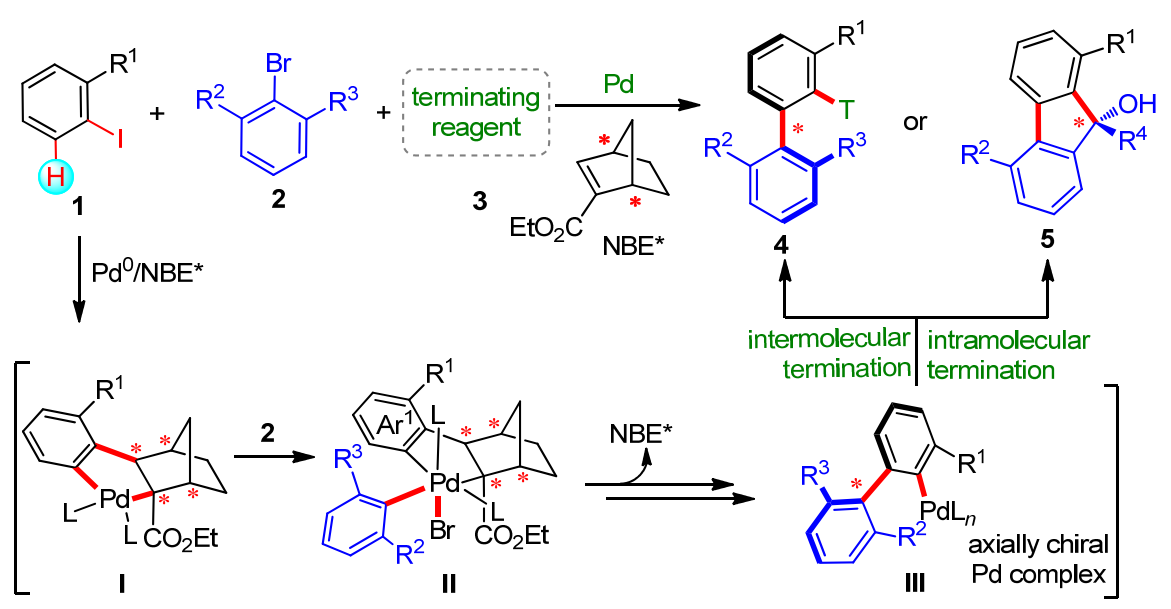

图式 1 钯/手性降冰片烯协同催化不对称 $\mathrm{C}-\mathrm{H}$ 芳基化反应

Scheme 1 Asymmetric $\mathrm{C}-\mathrm{H}$ arylation through $\mathrm{Pd} / \mathrm{NBE}^{*}$ cooperative catalysis

* Corresponding author. E-mail: xcwang@nankai.edu.cn. Published online October 23, 2020. 
基化合物. 除烯烃之外, 其他类型的终止试剂也能适用, 如炔烃、烷基硼酸、芳基嗍酸、㲵化物、酮等. 随后, 作 者考察了芳基碘化物的适用性, 卤素、烷氧基、酯基等 不同官能团取代的底物都能以优秀的对映选择性得到 目标产物. 最后, 作者研究了芳基溴化物的普适性, 发 现底物至少含有一个拉电子基团, 如酯基、酰胺基、羧 基和硝基等, 才可以兼顾反应活性和对映选择性. 另外, 作者还发现当溴的邻位是酰基时, 可以实现轴手性向中 心手性的高效转移, 以极高的对映选择性得到手性芴醇 类化合物.

更重要的是, 反应所得的轴手性联芳基产物可以方 便地转化为新型的轴手性配体/催化剂. 例如, 产物 6 经 过一步转化得到轴手性膦-烯配体 7, 该配体在钯催化 的不对称烯丙基化反应中表现出优秀的反应活性和对 映选择性 (Scheme 2). 此外, 产物 8 经过简单转化, 不仅 可以得到 Guo 催化剂的类似物 ${ }^{[7]}$, 还可以得到轴手性二 醛化合物 10 (Scheme 3); 从化合物 $\mathbf{1 0}$ 出发, 可以很方便 地制备其他结构的手性催化剂和手性配体 ${ }^{[8]}$.

周强辉课题组发展的 $\mathrm{Pd} / \mathrm{NBE} *$ 协同催化方法可以 模块化地构建轴手性联芳基化合物, 并且在制备手性配 体/催化剂方面具有很大的应用潜力. 由于芳基卤化物 来源广泛，终止反应类型丰富，该工作为合成手性联芳
基化合物提供了重要的新策略. 此外, 该工作也将推动 催化不对称 Catellani 反应的进一步发展.<smiles></smiles>

6 ( > 99\% ee)

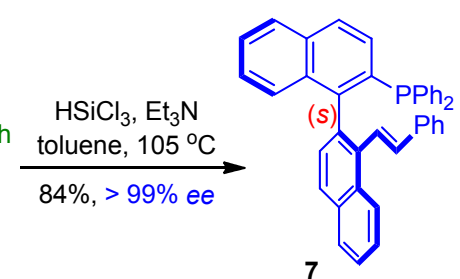

(phosphine-olefin ligand)

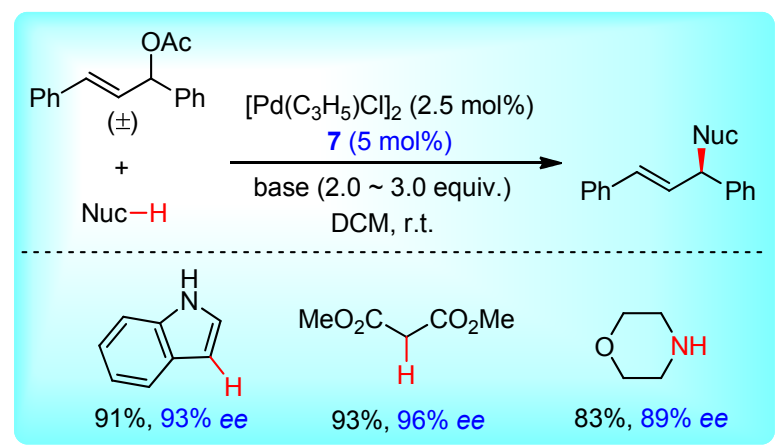

图式 2 所得轴手性配体在不对称烯丙基化反应中的应用 Scheme 2 Applications of axially chiral ligands in asymmetric allylation reactions

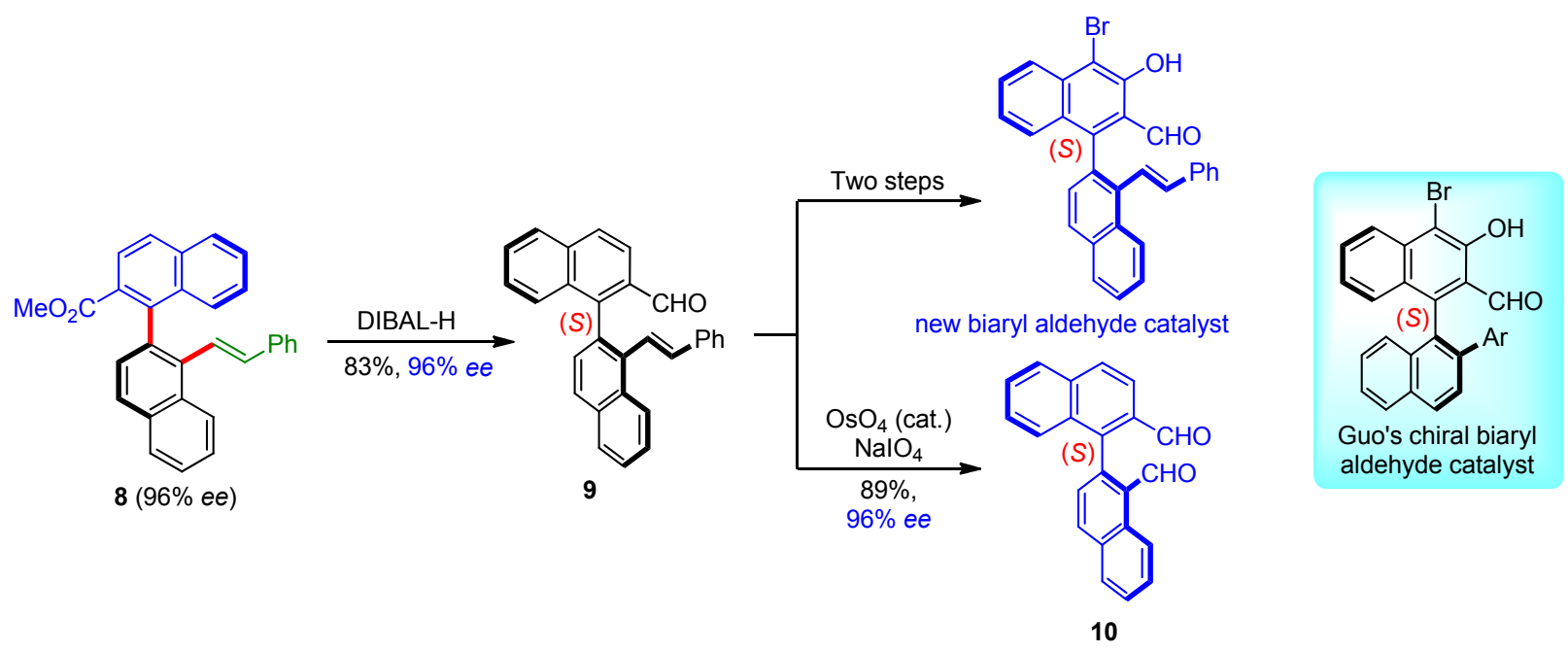

图式 3 轴手性联芳基产物的修饰

Scheme 3 Modification of axially chiral biaryls

\section{References}

[1] Kumarasamy, E.; Raghunathan, R.; Sibi, M. P.; Sivaguru, J. Chem. Rev. 2015, 115, 11239.

[2] Yamaguchi, K.; Yamaguchi, J.; Studer, A.; Itami, K. Chem. Sci. 2012, 3, 2165.

[3] Jia, Z.-J.; Merten, C.; Gontla, R.; Daniliuc, C. G.; Antonchick, A. P.; Waldmann, H. Angew. Chem., Int. Ed. 2017, 56, 2429.

[4] Jang, Y.-S.; Wozniak, Ł.; Pedroni, J.; Cramer, N. Angew. Chem., Int.
Ed. 2018, 57, 12901.

[5] Catellani, M., Motti, E.; Della Cá, N. Acc. Chem. Res. 2008, 41, 1512.

[6] Liu, Z.-S.; Hua, Y.; Gao, Q.; Ma, Y.; Tang, H.; Shang, Y.; Cheng, H.-G.; Zhou, Q. Nat. Catal. 2020, 3, 727.

[7] Wen, W.; Chen, L.; Luo, M.-J.; Zhang, Y.; Chen, Y.-C.; Ouyang, Q.; Guo, Q.-X. J. Am. Chem. Soc. 2018, 140, 9774.

[8] Witzig, R. M.; Fäseke, V. C.; Häussinger. D.; Sparr, C. Nat. Catal. 2019, 2, 925 . 